\title{
ESTUDO DA ESTABILIDADE FÍSICO-QUÍMICA DE SUCO DE ABACAXI 'PÉROLA'
}

\author{
Study of the psycho-chemical stability of 'Pérola' pineapple juice \\ Paulo Rogério Siriano Borges ${ }^{1}$, Elisangela Elena Nunes Carvalhoº ${ }^{2}$ Eduardo Valério de Barros Vilas Boas ${ }^{3}$, \\ Juliana Pinto de Lima ${ }^{4}$, Lucas Ferreira Rodrigues ${ }^{3}$
}

\begin{abstract}
RESUMO
Neste trabalho foram avaliadas as mudanças físico-químicas provocadas pelo tipo de armazenamento do suco de abacaxi 'Pérola', durante de 48 horas após sua elaboração. Foram avaliadas 4 condições de armazenamento, em ambiente refrigerado $\left(4 \pm 1^{\circ} \mathrm{C}\right)$ e em temperatura ambiente $\left(22 \pm 1^{\circ} \mathrm{C}\right)$, ambas com e sem luminosidade. $\mathrm{O}$ experimento foi conduzido em delineamento inteiramente casualizado, com os tratamentos dispostos em esquema fatorial $2 \times 2 \times 6$, sendo 2 ambientes de luminosidade (presença e ausência), 2 condições de temperatura (refrigeração e ambiente) e 6 tempos de amostragem $(0,6,12,24,36$ e 48 horas) com 3 repetições. Foram analisados, $\mathrm{pH}$, acidez titulável, sólidos solúveis, vitamina $\mathrm{C}$ total e cor utilizando-se as variáveis claridade $\left(\mathrm{L}^{*}\right)$, ângulo de cor $\left(\mathrm{h}^{\circ}\right)$ e cromaticidade $\left(\mathrm{C}^{*}\right)$. O tempo de armazenamento apresentou influência negativa na qualidade do suco provocando a diminuição dos teores de ácido ascórbico e ácido cítrico, alterações na cor, principalmente o escurecimento. Entretanto, quando armazenado em ambiente refrigerado e sem luz, o suco conservou suas características iniciais por mais tempo, sendo estas melhor preservadas pelas baixas temperaturas.
\end{abstract}

Termos para indexação: Ácido ascórbico, armazenamento, in natura.

\section{ABSTRACT}

In this work, psycho-chemical changes caused by the storage of homemade 'Pérola' pineapple juice, over 48 hours after its preparation were evaluated. Four storage conditions were evaluated in a refrigerated environment $\left(4 \pm 1^{\circ} \mathrm{C}\right)$ and in room temperature $\left(22 \pm 1^{\circ} \mathrm{C}\right)$ both in the presence and abscence of light. The experiment was conducted with a totally random design, with treatments arranged in a factorial $2 \times 2 \times 6$, with 2 light conditions (presence and absence), 2 temperature conditions (cooling and room temperature) and 6 sampling times $(0,6,12,24,36$ and 48 hours) with three replicates. $\mathrm{pH}$, titratable acidity, soluble solids, total vitamin $\mathrm{C}$ and color using the variables: luminosity $\left(\mathrm{L}^{*}\right)$, hue angle $\left(\mathrm{h}^{\circ}\right)$ and chromaticity $\left(\mathrm{C}^{*}\right)$ were analyzed. The period of storage presented a negative influence on the pineapple juice, causing a reduction of ascorbic and citric acid contents and color changes, mainly darkening. However, when stored in refrigerated environment in the abscence of light, the juice conserved its initial features for a longer time, which were better preserved by low temperatures.

Index terms: Ascorbic acid, storage, in natura.

(Recebido em 15 de abril de 2010 e aprovado em 4 de fevereiro de 2011)

\section{INTRODUÇÃO}

Segundo dados do Ministério da Agricultura (BRASIL, 2010), o Brasil é o terceiro maior produtor mundial de frutas, com um volume de 42,68 milhões de toneladas por ano, ficando atrás apenas da China e da Índia. Entretanto, apesar do consumo per capta de frutas no Brasil ter aumentado nos últimos anos, chegando a 2,5\% do total de calorias consumidas diariamente, esse valor ainda está distante do recomendado pela Organização Mundial de Saúde (OMS) e Food Agriculture Organization of the United Nations (FAO) que é de pelo menos 6 a 7\% (CLARO; MONTEIRO, 2010).
As frutas geralmente são constituídas de água, carboidratos, proteínas, vitaminas e sais minerais. Entretanto, a maior contribuição para a alimentação humana é com relação às fibras, vitaminas e sais minerais. Os minerais, cálcio e ferro e as vitaminas $\mathrm{A}, \mathrm{B}_{1}, \mathrm{~B}_{3}$ e $\mathrm{C}$ são as mais encontradas nas frutas (CHITARRA; CHITARRA, 2005). Esse valor alimentício se reveste de grande importância, principalmente, para as populações de baixa renda, que têm nesse alimento uma alternativa para suplementação alimentar. Sabe-se que uma mudança apropriada na dieta em relação à inclusão de frutas e seus derivados pode ser importante na prevenção de doenças e para uma vida mais saudável (BROEK, 1993; SHILS et al.,1994; BLENFORD, 1996).

1Universidade Federal de Lavras/UFLA - Cx. P. 3037 - 37200-000 - Lavras, MG - paulosiriano@uft.edu.br

${ }^{2}$ Universidade Federal do Tocantins/UFT - Gurupi, TO

${ }^{3}$ Universidade Federal de Lavras/UFLA - Departamento de Ciência dos Alimentos/DCA - Lavras, MG

${ }^{4}$ Universidade Federal de Lavras/UFLA - Lavras, MG 
Nesse contexto, as frutas tropicais destacam-se das demais, pelo seu sabor mais característico e aos altos teores de açúcares simples que lhes conferem sabor mais adocicado. Com base nessas características, destaca-se o abacaxi (Ananas comosus var. comosus), fruta que possui seu centro de origem na América do Sul (SOUZA; MELLETI, 1997) com qualidades sensoriais que o distinguem universalmente. Rico em açúcares, principalmente sacarose e açúcares redutores, possui valores apreciáveis de minerais como o potássio, magnésio e cálcio, além de ser fonte de vitaminas $\mathrm{A}_{\text {e }} \mathrm{B}_{1} \mathrm{e}$ considerado uma fonte aceitável de vitamina C. Outra característica importante é o fato de atuar como adjuvante na digestão, em razão do seu alto teor de bromelina, uma mistura de enzimas proteolíticas que, em meio ácido, básico ou neutro, transforma as matérias albuminóides em proteoses ou peptonas (MEDINA, 1987).

O suco de abacaxi de preparação caseira, sem conservantes, é muito consumido e apreciado em todo o mundo. $\mathrm{O}$ teor de vitaminas e minerais dos sucos de fruta pode variar dependendo da espécie, do estádio de maturação na época da colheita, de variações genéticas, do manuseio pós-colheita, das condições de estocagem, do processamento e do tipo de preparação elaborada (HOWARD et al., 1999; REDY; LOVE, 1999; COELHO et al., 2010), podendo influenciar na qualidade nutricional do alimento processado (HOWARD et al., 1999).

Paula et al. (2009), estudando produtos in natura de origem vegetal comercializados em Lavras - MG, Brasília DF e São Paulo - SP, detectaram falhas na manutenção da qualidade com base no $\mathrm{pH}$, acidez titulável e sólidos solúveis. Sendo assim, é importante que o consumidor conheça a melhor forma de armazenar sucos de frutas, para que possa aproveitar ao máximo seu conteúdo de nutrientes de forma segura (KABASAKALIS et al., 2000).

Sabe-se que o consumo de frutas in natura é responsável por $95 \%$ da ingestão de vitamina $\mathrm{C}$, também denominada de ácido ascórbico (VILAS-BOAS et al., 1999). Esse nutriente regulador tem importantes papéis no organismo humano, tais como a formação de tecido conjuntivo, transporte de íons e proteção das células contra radicais livres, em razão do seu forte poder antioxidante (BARATA-SOARES et al., 2004). Decorrente da instabilidade ao calor e luz, a vitamina C tem sido empregada como um indicador dos efeitos do processamento na retenção de nutrientes (GESTER, 1989; VANDERLISE et al., 1990; HOWARD et al., 1999).

Sabendo-se da importância do consumo de suco de frutas de preparação caseira para o fornecimento de nutrientes na alimentação e da necessidade de se conhecer a melhor forma de conservação das características físicoquímicas destes, neste trabalho, objetivou-se avaliar as mudanças provocadas pela forma de armazenamento do suco de abacaxi 'Pérola', de preparação caseira, ao longo de 48 horas após sua elaboração.

\section{MATERIAL E MÉTODOS}

\section{Processamento do suco de abacaxi}

O experimento foi realizado no Laboratório de Bioquímica e Fisiologia Pós-colheita de Frutos e Hortaliças do Departamento de Ciência dos Alimentos da Universidade Federal de Lavras. Foram utilizados abacaxis (Ananas comosus L. cv. Pérola) adquiridos no comércio de Lavras - MG. O processamento dos frutos foi feito manualmente, a $22^{\circ} \mathrm{C}$, com os utensílios (facas, baldes, escorredores, liquidificador e peneira) previamente sanificados, com solução de cloro a $200 \mathrm{mg} \mathrm{L}^{-1}$. Os operadores usaram luvas, aventais, gorros e máscaras, procurando proteger ao máximo o suco de prováveis contaminações.

As coroas foram retiradas e os frutos lavados em água corrente com escova e deixados em solução de cloro a $200 \mathrm{mg} \mathrm{L}^{-1}$ por 15 minutos para sanificação. Em seguida, os frutos foram descascados, picados e tiveram o cilindro central separado, sendo utilizada somente a polpa. A diluição do suco foi de uma parte de água para uma de polpa sem adição de açúcar.

\section{Tratamentos, delineamento experimental e análise estatística}

Amostras de $100 \mathrm{ml}$ foram armazenadas em frascos de vidro transparente tampados, com capacidade de $120 \mathrm{ml}$. O experimento foi conduzido em delineamento inteiramente casualizado (DIC), com os tratamentos dispostos em esquema fatorial $2 \times 2 \times 6$, sendo 2 ambientes de luminosidade (presença e ausência), 2 condições de temperatura (refrigeração e ambiente) 6 tempos de amostragem $(0,6,12,24,36$ e 48 horas) com 3 repetições. Para a condição de ausência de luminosidade os frascos foram cobertos com papel alumínio. A análise estatística foi realizada com o auxílio do programa SISVAR, foi realizado teste Tukey e análise de regressão à 5 e $1 \%$ de probabilidade mediante significância do teste $\mathrm{f}$.

\section{Análises físico químicas}

Foram determinados $\mathrm{pH}$, por meio de potenciômetro (TECNAL ${ }^{\mathrm{TM}}$ Tec-3 MP), sólidos solúveis por meio de refratômetro (Reichert AR200), acidez titulável expressa em conteúdo de ácido cítrico (ASSOCIATION OF OFFICIAL 
ANALYTICAL CHEMISTRY - AOAC, 1997), ratio entre sólidos solúveis e acidez titulável (ratio $=\mathrm{SS} / \mathrm{AT}$ ), vitamina $\mathrm{C}$ total pelo método espectrofotométrico, utilizando 2,4-dinitrofenilhidrazina (STROHERCHER; HENNING, 1967), coloração utilizando-se de reflectômetro Minolta (Chroma Meter CR-400), que se expressa segundo o sistema proposto pela Commission Internacionale de L'Eclaraige (CIE) em L* $\mathrm{a}^{*} \mathrm{~b}^{*}$ (color space) o que permitiu determinar a claridade $\left(\mathrm{L}^{*}\right)$, o ângulo de cor $\left(\mathrm{h}^{\circ}\right)$ e a cromaticidade (C*) (McGUIRE, 1992).

\section{RESULTADOS E DISCUSSÃO}

O suco de abacaxi recém preparado apresentou valor do ratio SS/AT de 17,19 $\pm 1,5$ que indica provável gosto doce. Em relação à coloração do suco, este mostrou-se amarelo-claro pouco pigmentado (Tabela 1). Pinheiro et al. (2006), verificando a qualidade química e físico-química de sucos concentrados de abacaxi detectaram para as variáveis $\mathrm{pH}(3,46$ a 3,63), ácido cítrico $\left(0,68\right.$ a $\left.0,98 \mathrm{~g} .100 \mathrm{~g}^{-1}\right)$ e ratio SS/AT (12,7 a 17,6) valores semelhantes aos encontrados neste trabalho (Tabela 1). Entretanto, os teores de sólidos solúveis foram superiores aos encontrados no suco de abacaxi 'Pérola' de preparação caseira, ficando entre 11,2 e 13,5 ${ }^{\circ}$ Brix, uma vez que se tratou de um suco concentrado. Já, a vitamina $C$ variou entre 5,8 e $14,1 \mathrm{mg} .100 \mathrm{~g}^{-1}$, valores bem abaixo dos encontrados no presente estudo. Confirmando que, se preparado com a fruta in natura, o suco de abacaxi pode ser uma fonte aceitável de vitamina $\mathrm{C}$, uma vez que um copo de aproximadamente $250 \mathrm{~g}$ do suco apresentaria $130 \%$ da recomendação diária para um adulto, que é de $45 \mathrm{mg}$, segundo a Agência Nacional de Vigilância Sanitária - ANVISA (2004).
Houve aumento nos valores de $\mathrm{pH}$ até as primeiras 24 horas, seguido de diminuição. Menores variações no $\mathrm{pH}$ foram determinadas pela refrigeração, sendo que o $\mathrm{pH}$ do suco armazenado à temperatura ambiente foi superior ao do suco refrigerado a partir das 24 horas (Figura 1). Isso demonstra que a refrigeração foi eficiente na manutenção dos valores de $\mathrm{pH}$ ao longo do armazenamento. Chitarra e Chitarra (2005) afirmam que numa faixa de concentração de ácidos entre 0,5 e 2,5\%, o pH aumenta com a redução da acidez e que esta pequena variação no $\mathrm{pH}$ é bem detectável nos testes sensoriais.

Para o ácido cítrico, houve interação significativa entre tempo e luminosidade $(\mathrm{p}<0,05)$ com tendência de aumento, tanto no suco armazenado em ambiente sem luz $(\mathrm{p}<0,05)$, quanto no armazenado em ambiente com luz $(\mathrm{p}<0,01)$ (Figura 2). Nota-se também uma resposta inversa à do $\mathrm{pH}$, uma vez que houve tendência de diminuição até as primeiras 24 horas seguida de aumento. Sabe-se que variações na acidez titulável traduzem as variações no $\mathrm{pH}$ (TEISSON, 1979).

Os níveis de ácido cítrico foram significativamente superiores no suco quando armazenados na ausência de luz após 12, 36 e 48 horas (Figura 2) e na média dos tempos, apresentando valores de $0,42 \mathrm{~g} .100 \mathrm{~g}^{-1}$ para ambiente sem luz e de $0,40 \mathrm{~g} .100 \mathrm{~g}^{-1}$ para ambiente com luz. Além disso, o suco armazenado na ausência de luz alcançou, ao final do período de armazenamento, valores estatisticamente iguais aos iniciais $\left(0,43\right.$ e 0,46 g. $100 \mathrm{~g}^{-1}$, respectivamente) indicando que essa condição é mais favoráveis para a preservação dessa característica, Chitarra e Chitarra (2005) afirmam que a luz é um dos fatores que alteram de forma negativa a qualidade dos alimentos ao longo do armazenamento.

Tabela 1 - Caracterização inicial do suco de abacaxi 'Pérola' de preparação caseira para as variáveis ácido ascórbico (AA), pH, sólidos solúveis (SS), acidez titulável (AT), ratio (SST/AT) claridade $(* \mathrm{~L})$, ângulo de cor $\left({ }^{\circ} \mathrm{h}\right)$ e cromaticidade $\left(\mathrm{C}^{*}\right)$.

\begin{tabular}{ccc}
\hline Variável & Unidade & Valores \\
\hline Ácido ascórbico (AA) & $\mathrm{mg} .100 \mathrm{~g}^{-1}$ & $23,40 \pm 1,18$ \\
$\mathrm{pH}$ & - & $3,74 \pm 0,01$ \\
Sólidos solúveis (SS) & ${ }^{\circ}$ Brix & $7,33 \pm 0,05$ \\
Acidez titulável (AT) & $\mathrm{g} \cdot 100 \mathrm{~g}^{-1}$ & $0,43 \pm 0,04$ \\
ratio $(\mathrm{SST} / \mathrm{AT})$ & - & $17,19 \pm 1,5$ \\
Claridade (L $\mathrm{L}^{*}$ & - & $25,78 \pm 0,05$ \\
Ângulo de cor $\mathrm{h}^{\circ}$ & - & $50,17 \pm 8,49$ \\
Cromaticidade $\mathrm{C}^{*}$ & - & $1,29 \pm 0,53$ \\
\hline
\end{tabular}

*Médias e desvio padrão de 3 repetições. 


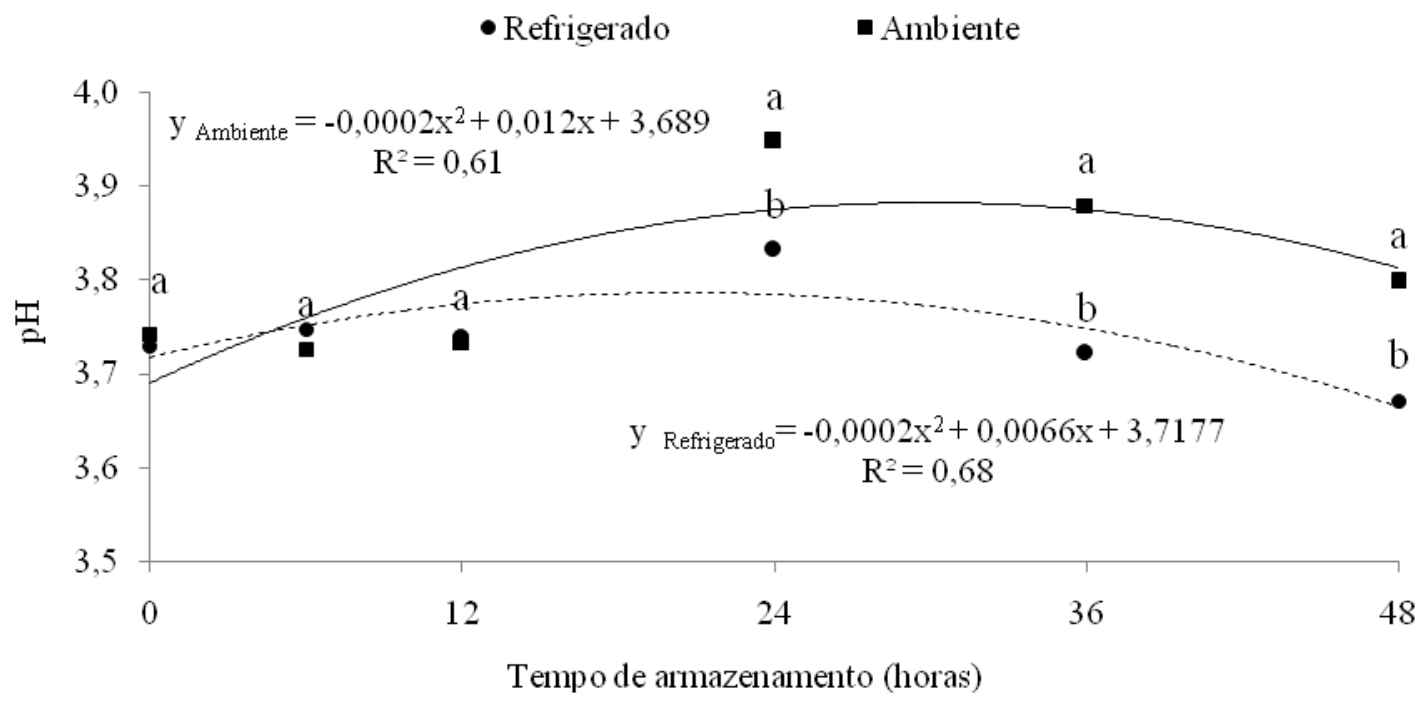

Figura 1 - Valores de pH de suco de abacaxi 'Pérola' de preparação caseira armazenado sob refrigeração e temperatura ambiente ao longo de 48 horas de armazenamento, interação entre tempo e temperatura significativa ( $\mathrm{p}<0,01)$, valores seguidos de letras diferentes no mesmo tempo de amostragem diferem entre si pelo teste de Tukey a $1 \%$ de probabilidade.

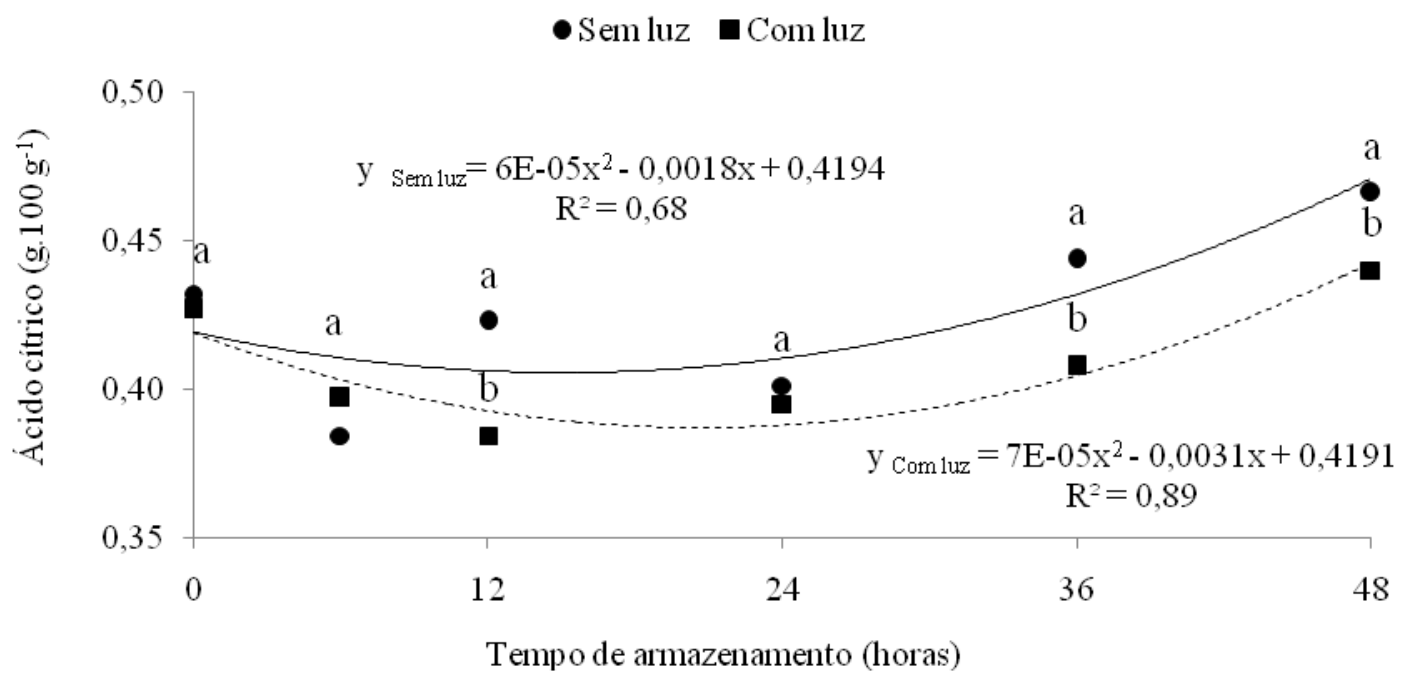

Figura 2 - Valores de ácido cítrico de suco de abacaxi 'Pérola' de preparação caseira armazenado em temperatura ambiente e na geladeira ao longo de 48 horas de armazenamento, interação entre tempo e temperatura significativa $(p<0,05)$ valores seguidos de letras diferentes no mesmo tempo de amostragem diferem entre si pelo teste de Tukey a $1 \%$ de probabilidade.

Apesar de ter ocorrido interação significativa entre luminosidade, temperatura e tempo $(\mathrm{p}<0,01)$ para o teor de sólidos solúveis (SS), não foi verificado um modelo de regressão ajustável $(\mathrm{p}<0,05)$, pois houve pouca variação nos valores de SS no suco de abacaxi de preparação caseira ao longo das avaliações, com uma média de $7,44 \pm 0,11^{\circ}$ Brix. Giacomelli (1982) e Gorgatti Netto et al. (1996) encontraram valores semelhantes de SS para o abacaxi 'Pérola'.
Na Tabela 2, onde se encontram os dados de interação entre níveis de luminosidade, temperatura e horas, observa-se que às 36 horas em temperatura ambiente e ausência de luminosidade, o suco apresentou menor conteúdo de $\mathrm{SS}$, e às 48 horas o suco armazenado em temperatura ambiente apresentou redução no conteúdo de sólidos solúveis, tanto na presença quanto na ausência de luz. Esses dados demonstram que a temperatura baixa 
foi mais eficiente na preservação dos teores de SS e que a presença de luminosidade só afetou negativamente esses teores quando combinada com a temperatura alta. Segundo Chitarra e Chitarra (2005), a diminuição dos valores de SS pode resultar em perda nas características sensoriais, uma vez que esta variável representa o teor de sólidos diluídos na solução, entre eles os açúcares.

Os teores de vitamina $\mathrm{C}$ variaram significativamente em função dos fatores tempo e temperatura isoladamente. Ocorreu degradação média de vitamina $\mathrm{C}(\mathrm{p}<0,01)$ no suco de abacaxi de 6,24 $\mathrm{mg} \mathrm{g}^{-1}$, ao longo das 48 horas, seguindo uma equação de primeiro grau (Figura 3), conforme também verificado por Chan e Yamammoto (1994), Yamashita e Benassi (2000) e Silva (2010).

De acordo com Udin et al. (2002), a equação de primeiro grau parece ser a que melhor descreve a perda de vitamina $\mathrm{C}$ sob diferentes condições de armazenamento. Como a deterioração pode seguir diferentes rotas simultaneamente, principalmente num suco onde a estrutura celular é destruída e enzimas e substratos permanecem no mesmo meio, a mudança na vitamina $\mathrm{C}$ medida é resultado combinado de diferentes rotas que geram um comportamento linear de degradação. Isso mostra que, quanto maior o estresse causado pelo preparo, maior a perda desta vitamina, o que também foi observado por Martin et al. (1978), que destacaram a importância da escolha dos equipamentos e dos métodos de processamento na manutenção das características iniciais do suco.

A refrigeração foi efetiva na minimização das perdas de vitamina $C$, com valores estatisticamente superiores (21,0 $\left.\mathrm{mg} \mathrm{g}^{-1}\right)$ em relação ao ambiente não refrigerado. Sarzi e Durigan (2002), avaliando produtos minimamente processados de abacaxi 'Pérola', concluíram que o aumento na temperatura de armazenamento favoreceu a redução nos teores de ácido ascórbico, sendo esse o fator decisivo para a manutenção da qualidade do produto.

Tabela 2 - Desdobramento para a interação entre níveis de luminosidade (presença e ausência), temperatura (refrigerado e ambiente) e tempo ( $0,6,12,24,36$ e 48 horas) para a variável sólidos solúveis (SS) em suco de abacaxi 'Pérola' de preparação caseira.

\begin{tabular}{|c|c|c|}
\hline \multirow{3}{*}{ Temperatura } & \multicolumn{2}{|c|}{ Luminosidade } \\
\hline & Ausência & Presença \\
\hline & \multicolumn{2}{|c|}{0 horas } \\
\hline Refrigerado & 7,35 Aa & $7,35 \mathrm{Aa}$ \\
\hline \multirow[t]{2}{*}{ Ambiente } & 7,35 Аa & 7,35 Aa \\
\hline & \multicolumn{2}{|c|}{6 horas } \\
\hline Refrigerado & 7,36 Aa & $7,30 \mathrm{Aa}$ \\
\hline \multirow[t]{2}{*}{ Ambiente } & 7,33 Aa & 7,33 Aa \\
\hline & \multicolumn{2}{|c|}{12 horas } \\
\hline Refrigerado & $7,46 \mathrm{Aa}$ & $7,53 \mathrm{Aa}$ \\
\hline \multirow[t]{2}{*}{ Ambiente } & 7,53 Аa & 7,50 Aa \\
\hline & \multicolumn{2}{|c|}{24 horas } \\
\hline Refrigerado & 7,57 Aa & 7,53 Aa \\
\hline \multirow[t]{2}{*}{ Ambiente } & $7,50 \mathrm{Aa}$ & 7,50 Aa \\
\hline & \multicolumn{2}{|c|}{36 horas } \\
\hline Refrigerado & 7,46 Aa & $7,40 \mathrm{Aa}$ \\
\hline \multirow[t]{2}{*}{ Ambiente } & 7,30 Ba & 7,33Aa \\
\hline & \multicolumn{2}{|c|}{48 horas } \\
\hline Refrigerado & 7,70 Aa & 7,70 Aa \\
\hline Ambiente & 7,58 Ba & 7,36 Bb \\
\hline
\end{tabular}

Valores seguidos de mesma letra minúscula na horizontal e maiúscula na vertical dentro de um mesmo tempo de amostragem, não diferem entre si pelo teste de Tukey a $1 \%$ de probabilidade. 
A claridade $\left(\mathrm{L}^{*}\right)$ variou significativamente ao longo do armazenamento e em função da interação entre temperatura e luminosidade. Houve tendência de escurecimento do suco com a redução da claridade $\left(\mathrm{L}^{*}\right)$ ao longo do armazenamento (Figura 4). O suco armazenado sob refrigeração e na ausência de luz também se manteve mais claro (Tabela 3).

A degradação da vitamina $\mathrm{C}$ (Figura 3) é um dos fatores que pode ser responsável pelo escurecimento, uma vez que compostos indesejáveis como furfural e hidroximetilfurfural são gerados nesse processo e estes têm sido altamente correlacionados com o escurecimento de sucos de fruta, levando ainda à deterioração do sabor e da qualidade, aliada à redução da vida útil e à perda do valor nutricional (TANNENBAUM et al., 1985; LEE; CHEN, 1998; LEE; COGATES, 1999). Esse escurecimento também foi observado por Martin et al. (1978) que afirmam que o processo de escurecimento é decorrente de reações químicas e bioquímicas, consequentes ao processamento, principalmente em razão do contato das polifenoloxidases com seus substratos.

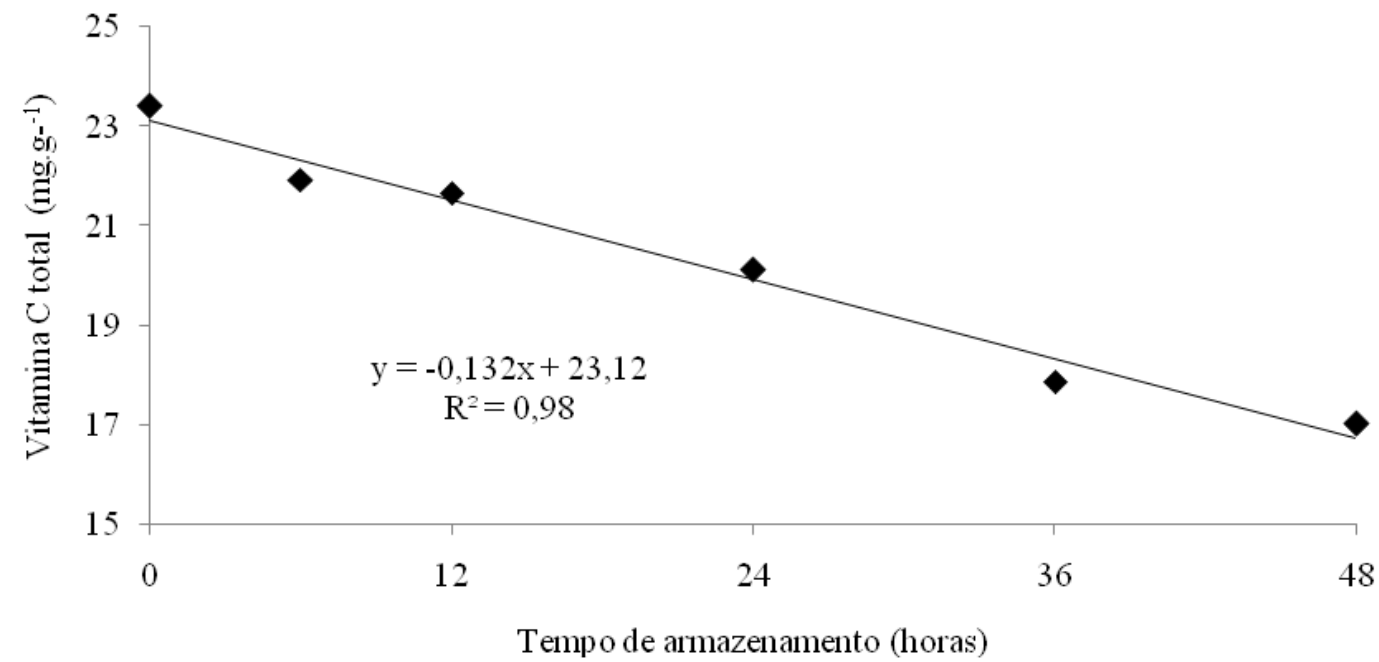

Figura 3 - Valores de vitamina $\mathrm{C}$ total de suco de abacaxi 'Pérola' de preparação caseira ao longo de 48 horas de armazenamento $(\mathrm{p}<0,01)$.

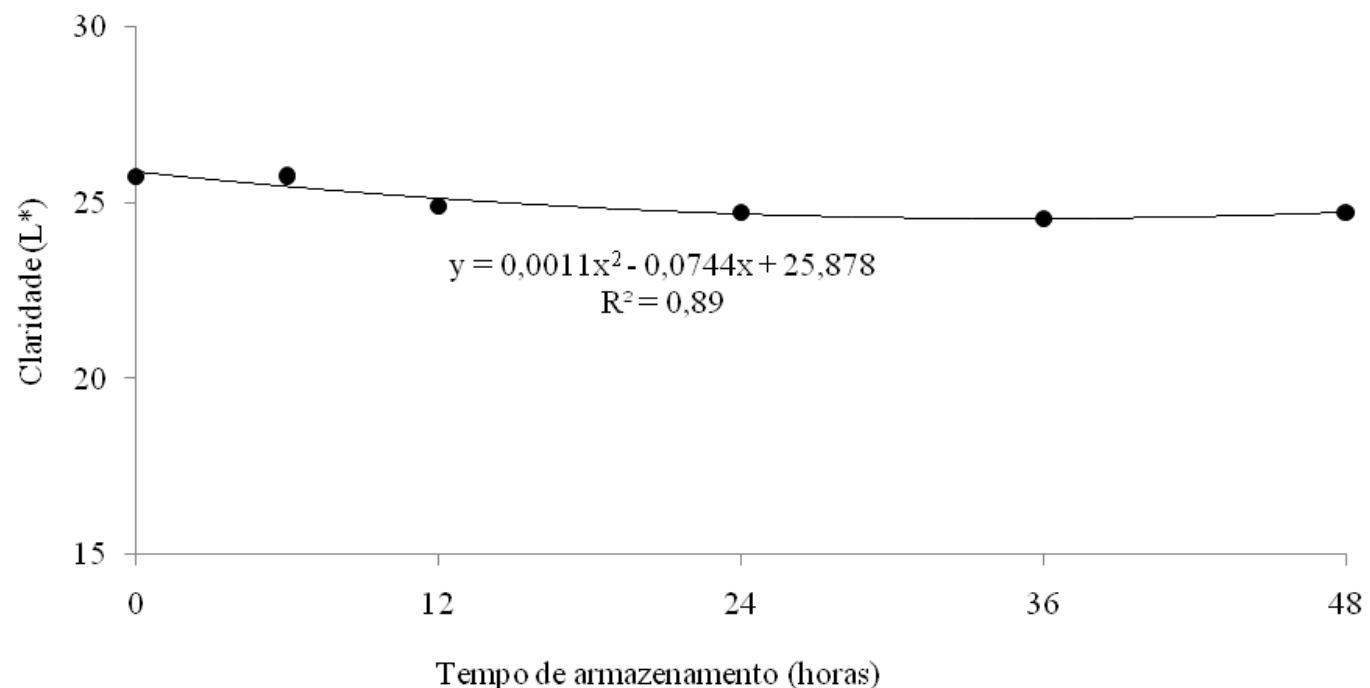

Figura 4 - Valores de claridade $\left(\mathrm{L}^{*}\right)$ para suco de abacaxi 'Pérola' de preparação caseira ao longo de 48 horas de armazenamento $(\mathrm{p}<0,05)$. 
Para o ângulo de cor $\left(\mathrm{h}^{\circ}\right)$, houve tendência de aumento ao longo do armazenamento (Figura 5), demonstrando que o suco tendeu a ficar mais amarelado. SOUTO et al. (2004), trabalhando com abacaxi 'Pérola' minimamente processado também encontraram aumento no $\mathrm{h}^{\mathrm{o}}$, indicando que a polpa com o armazenamento ficou mais pigmentada. Os valores de $\mathrm{h}^{\mathrm{o}}$ foram significativamente superiores na temperatura ambiente (Tabela 4), indicando que na geladeira houve preservação das características iniciais da cor do suco.
A cromaticidade $\left(\mathrm{C}^{*}\right)$ também foi afetada de forma significativa pelo tempo de armazenamento ( $\mathrm{p}<0,01)$, entretanto, sem modelo de regressão ajustável. Na Tabela 5, encontram-se os valores de $\mathrm{C}^{*}$, nota-se que ocorreu aumento dessa variável quando na ausência de luz e sob alta temperatura, demonstrando que a presença de luz por si só não afetou de forma relevante a intensidade da cor do suco. SOUTO et al. (2004), trabalhando com abacaxi 'Pérola' minimamente processado detectaram aumento dos valores de $C^{*}$ da polpa, indicando aumento na quantidade de pigmentos.

Tabela 3 - Desdobramento para a interação entre níveis de luminosidade (presença e ausência) e temperatura (refrigerado e ambiente) para a variável claridade ( $\left.\mathrm{L}^{*}\right)$.

\begin{tabular}{ccc}
\hline & \multicolumn{2}{c}{ Luminosidade } \\
\cline { 2 - 3 } Temperatura & Ausência & Presença \\
\hline Refrigerado $\left(4 \pm 1^{\circ} \mathrm{C}\right)$ & $25,47 \mathrm{Aa}$ & $25,06 \mathrm{Aa}$ \\
Ambiente $\left(22 \pm 1^{\circ} \mathrm{C}\right)$ & $24,50 \mathrm{Bb}$ & $25,31 \mathrm{Aa}$ \\
\hline
\end{tabular}

Valores seguidos de mesma letra minúscula na horizontal e maiúscula na vertical, não diferem entre si pelo teste de Tukey a $1 \%$ de probabilidade.

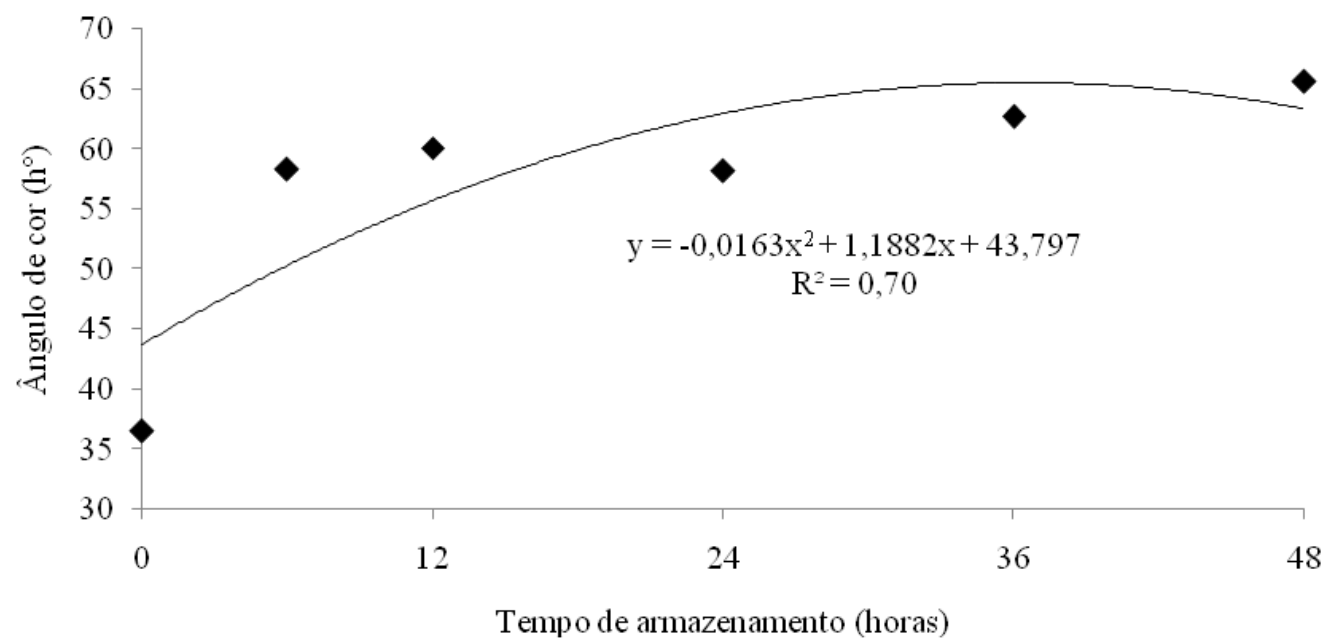

Figura 5 - Valores de ângulo de cor $\left(\mathrm{h}^{\circ}\right)$ para suco de abacaxi pérola de preparação caseira ao longo, de 48 horas de armazenamento $(\mathrm{p}<0,05)$.

Tabela 4 - Desdobramento para a interação entre níveis de luminosidade (presença e ausência) e temperatura (refrigerado e ambiente) para a variável ângulo de cor $\left(\mathrm{h}^{\circ}\right)$.

\begin{tabular}{ccc}
\hline & \multicolumn{2}{c}{ Luminosidade } \\
\cline { 2 - 3 } Temperatura & Ausência & Presença \\
\hline Refrigerado $\left(4 \pm 1^{\circ} \mathrm{C}\right)$ & $57,20 \mathrm{Ba}$ & $60,41 \mathrm{Aa}$ \\
Ambiente $\left(22 \pm 1^{\circ} \mathrm{C}\right)$ & $63,99 \mathrm{Aa}$ & $60,07 \mathrm{Aa}$ \\
\hline
\end{tabular}

Valores seguidos de mesma letra minúscula na horizontal e maiúscula na vertical, não diferem entre si pelo teste de Tukey a $1 \%$ de probabilidade. 
Tabela 5 - Desdobramento para a interação entre níveis de luminosidade (presença e ausência) e temperatura (refrigerado e ambiente) para a variável cromaticidade $\left(\mathrm{C}^{*}\right)$.

\begin{tabular}{ccc}
\hline & \multicolumn{2}{c}{ Luminosidade } \\
\cline { 2 - 3 } Temperatura & Ausência & Presença \\
\hline Refrigerado $\left(4 \pm 1^{\circ} \mathrm{C}\right)$ & $1,63 \mathrm{Ba}$ & $1,89 \mathrm{Aa}$ \\
Ambiente $\left(22 \pm 1^{\circ} \mathrm{C}\right)$ & $2,20 \mathrm{Aa}$ & $1,86 \mathrm{Ab}$ \\
\hline
\end{tabular}

Valores seguidos de mesma letra minúscula na horizontal e maiúscula na vertical, não diferem entre si pelo teste de Tukey a $1 \%$ de probabilidade.

\section{CONCLUSÃO}

O tempo de armazenamento influenciou negativamente a qualidade do suco de abacaxi 'Pérola', de preparação caseira, provocando a diminuição dos teores de ácido ascórbico e ácido cítrico, além de alterações nos sólidos solúveis, pH e cor, principalmente o escurecimento. Entretanto, se armazenado em ambiente refrigerado e sem luz, o suco conserva suas características iniciais por mais tempo, sendo estas melhor preservadas pelas baixas temperaturas.

\section{REFERÊNCIAS BIBLIOGRÁFICAS}

AGÊNCIA NACIONAL DE VIGILÂNCIA SANITÁRIA. Consultoria Pública n ${ }^{\circ}$ 80, de 13 de dezembro de 2004. Brasília, 2004. Disponível em: <hittp://Www4 anvisa.govi. br/base/visadoc/CP/CP\%5B8989-1-0\% 5 D.PDF $>$. Acesso em: 18 jan. 2011.

\section{ASSOCIATION OF OFFICIAL ANALYTICAL CHEMISTS. Official methods of analysis of the Association of Agricultural Chemists. 15.ed. Washington, 1997. v.2.}

BARATA-SOARES, A.D. et al. Ascorbic acid biosynthesis: a precursor study on plants. Brazilian Journal of Plant Physiology, Campinas, v.16, n.3, p.147154, 2004.

BLENFORD, D.E. Winner drinks: use of amino acids and peptides in sports nutrition. International Food Ingredients, Warsal, v.3, p.20 June 1996.

BRASIL. Ministério da Agricultura, Pecuária e Abastecimento. Anuário brasileiro da fruticultura. Brasília, 2010. 127p.

BROEK, A.V.D. Functional foods: the Japanese approach. International Food Ingredients, Warsal, v.1/2, p.4-10, 1993.
CHAN, H.T.; YAMAMOTO, H.Y. Kinects of anthocyanin decomposition in acerola juice. Journal of Food Science, Chicago, v.9, n.4, p.132-135, 1994.

CHITARRA, M.I.F.; CHITARRA, A.B. Pós-colheita de frutas e hortaliças: fisiologia e manuseio. Lavras: ESAL, 2005. 783p.

CLARO, R.M.; MONTEIRO, C.A. Renda familiar, preço de alimentos e aquisição domiciliar de frutas e hortaliças no Brasil. Revista de Saúde Pública, São Paulo, v.44, n.6, p.1014-1020, 2010.

COELHO, A.A.; CENCI, S.A.; RESENDE, E.D. de. Qualidade do suco de maracujá-amarelo em diferentes pontos de colheita e após o amadurecimento. Ciência e Agrotecnologia, Lavras, v.34, n.3, p.722-729, maio/jun. 2010.

GESTER, H. Vitamin losses with microwave cooking. Food Sciences and Nutrition, Cleveland, v.42F, p.173181, 1989.

\section{GIACOMELLI, E.J. Expansão da abacaxicultura no} Brasil. Campinas: Fundação Cargill, 1982. 72p.

GORGATTI NETTO, A. et al. Abacaxi para exportação: procedimentos de colheita e pós-colheita. Brasília: Embrapa-SPI, 1996. 41p. (Série Publicações Técnicas FRUPEX, 23).

HOWARD, L.A. et al. $\beta$-carotene and ascorbic acid retention in fresh and processed vegetables.

Journal of Food Science, Chicago, v.64, n.5, p.929936, 1999.

KABASAKALIS, V.; SIOPIDOU, D.; MOSHATOU, E. Ascorbic acid content of commercial fruit juices and its rate of loss upon storage. Food Chemistry, Amsterdam, v.70, n.3, p.325-328, 2000 . 
LEE, H.S.; CHEN, C.S. Rates of vitamin C loss and discoloration in clear orange juice concentrate during storage at temperature of $4-24^{\circ} \mathrm{C}$. Journal of

Agricultural and Food Chemistry, Washington, v.46, p.4723-4727, 1998.

LEE, H.S.; COGATES, G.A. Vitamin C in frozen, fresh squezeed, unpasteurized, polyethylene-bottled, orange juice: a storage study. Food Chemistry, Amsterdam, v.65, p.165-168, 1999.

MARTIN, Z.J. de et al. Processamento: produtos e subprodutos, características e utilização. In: MEDINA, J.C. et al. Abacaxi: da cultura ao processamento. Campinas: ITAL, 1978. p.69-94.

MCGUIRE, R.G. Reporting of objective color measurements. HortScience, Davis, v.27, n.12, p.12541255, Dec. 1992.

MEDINA, J.C. Abacaxi. Campinas: Instituto de Tecnologia de Alimentos, 1987. 285p. (Série Frutos Tropicais, 2).

PAULA, N.R.F. de et al. Qualidade de produtos minimamente processados e comercializados em gôndolas de supermercados nas Cidades de Lavras, MG, Brasília, DF e São Paulo, SP. Ciência e Agrotecnologia, Lavras, v.33, n.1, p.219-227, jan./fev. 2009.

PINHEIRO, M.A. et al. Avaliação química, físico-química e microbiológica de sucos de frutas integrais: abacaxi, caju e maracujá. Ciência e Tecnologia de Alimentos, Campinas, v.26, n.1, p.98-103, jan./mar. 2006.

REDY, M.B.; LOVE, M. The impact of food processing on the nutritional quality of vitamins and minerals. Impact of Processing on Food Safety, Chicago, v.459, p.99 106, 1999.

SARZI, B.; DURIGAN, J.F. Avaliação física e química de produtos minimamente processados de abacaxi 'Pérola'. Revista Brasileira de Fruticultura, Jaboticabal, v.24, n.2, p.333-337, ago. 2002.

SHILS, M.E.; OLSON, J.A.; SHIKE, M. Modern nutrition in health and disease. Philadelphia: Lea \& Febiger, 1994. 2v.
SILVA, D.S. da et al. Estabilidade de componentes bioativos do suco tropical de goiaba não adoçado obtido pelos processos de enchimento a quente e asséptico. Ciência e Tecnologia de Alimentos, Campinas, v.30, n.1, p.237-243, jan. 2010.

SOUTO, R.F. et al. Conservação pós-colheita de abacaxi 'Pérola' colhido no estádio de maturação "pintado" associando-se refrigeração e atmosfera modificada.

Revista Brasileira de Fruticultura, Jaboticabal, v.26, n.1, p.24-28, abr. 2004.

SOUZA, J.S.I.; MELETTI, L.M.M. Maracujá: espécies, variedades, cultivo. Piracicaba: FEALQ, 1997. 179p.

STROHERCHER, R.L.; HENNING, H.M. Análisis de vitaminas: métodos comprobados. Madrid: Paz Montalvo, 1967. 428p.

TANNENBAUM, S.R.; ARCHER, V.R.; YOUNG, M.C. Vitamins and minerals. In: FENEMA, O.R. (Ed.). Food chemistry. New York: M. Dekker, 1985. p.488-493.

TEISSON, C. Le brunissement interne de l'ananas: Ihistorique; II-material et méthodes. Fruits, Paris, v.34, n.4, p.245-281, avr. 1979.

UDIN, M.S.; HAWLADER, M.N.A.; MUJUMDAR, A.S. Degradation of ascorbic acid in dried guava during storage. Journal of Food Engineering, London, v.51, p.21-26, 2002.

VANDERLISE, J.T. et al. Ascorbic acid and dehydroascorbic acid content of food-as-eaten. Journal of Food Composition and Analisys, Oxford, v.3, p.105$118,1990$.

VILAS-BOAS, E.V. de B. Alimentos e nutrientes. Lavras: FAEPE, 1999. 70p.

YAMASHITA, F.; BENASSI, M.T. Influência da embalagem de atmosfera modificada e do tratamento com cálcio na cinética de degradação de ácido ascórbico e perda de massa em goiabas (Psidium guajava $\mathrm{L}$.).

Ciência e Tecnologia de Alimentos, Campinas, v. 23, n. 1, jan./abr., 2000. 